\title{
An Improved Modulation Strategy on Boost Soft-Switching Converter
}

\author{
Yingjie Xiong1, 2 \\ ${ }^{1}$ Shangrao Power Supply Branch, Jiangxi Electric Power Company, State Grid, 334000, China. \\ 2 Key Laboratory of Facility Agriculture Measurement and Control Technology and Equipment of Machinery \\ Industry, College of Electrical and Information Engineering, Jiangsu University, Zhenjiang 212013, China.
}

* Corresponding author. Email: 252622589@qq.com

Manuscript submitted July 10, 2017; accepted August 28, 2017.

doi: 10.17706/ijcee.2017.9.2.465-475

\begin{abstract}
In order to improve the modulation strategy of zero-voltage zero-current transition boost converter, an improved modulation strategy was put forward in this paper. The main switch can only achieve zero-current turn-on under traditional modulation strategy. However, the change to the turn-on time of main switch can make the main switch achieve zero-voltage zero-current turn-on, and the change to the turn-off time of auxiliary switch can realize the zero-voltage zero-current turn-off of auxiliary switch in advance as well. The simulation results verify the correctness of improvement.
\end{abstract}

Key words: Modulation strategy, boost converter, zero-voltage zero-current turn-off.

\section{Introduction}

Whether electric appliances and electronic devices have broad market is related to their performance, size, cost and power consumption [1], [2]. But transformers, inductors, and capacitors can hardly meet the need of volume and weight in practical engineering application. With the increase of switch frequency, the voltage and current cannot be zero at the same time, leading to generate overlapping region[ 3], [4], when the switch is turned on(or turned off). The switch working in hard-switching state produce switch loss. The introduction of soft-switching technology can eliminate the power loss of switch completely by adding small inductors, capacitors and other components in the circuit, whose principle is the resonance between the inductor and capacitor [5], [6].

Zero transition PWM circuit, including zero-current transition PWM circuit and zero-voltage transition PWM circuit [7], [8], is applied extensively in different circuits. There are two methods to improve circuit working efficiency [9], the first method is to improve the modulation strategy, another method is to improve the circuit working efficiency. This study is based on the second method. In paper [10], a zero-current zero-voltage transition PWM boost converter was put forward, which was formed by the application of zero transition circuit into boost converter and whose main switch can achieve zero-current turn-on under traditional modulation strategy. The change to the modulation strategy can make main switch achieve zero-voltage zero-current turn-on and auxiliary switch achieve zero-voltage zero-current turn-off in advance.

\section{Boost Soft-Switching Converter Working Principle and Mode Analysis}

\subsection{Boost Soft-Switching Converter Circuit Working Principle}


The boost soft-switching converter in Fig. 1 is the circuit proposed in paper [9], which contains zero-current transition PWM circuit within the dotted line. The zero-current transition PWM circuit is applied into boost circuit, which can get zero-current turn-on and zero-voltage turn-off of main switch $\mathrm{S}_{1}$ and zero-current turn-on and zero-current zero-voltage turn-off of auxiliary switch $S_{2}$. The input inductor is split into two split inductors $L_{1} 、 L_{2}$, while the resonant branch consist of two diodes $D_{1} 、 D_{3}$, resonant inductors $\mathrm{L}_{1} 、 \mathrm{~L}_{2} 、 \mathrm{~L}_{3}$, resonant capacitor $\mathrm{C}_{1}$ and auxiliary switch $\mathrm{S}_{2}$ with anti-parallel diode.

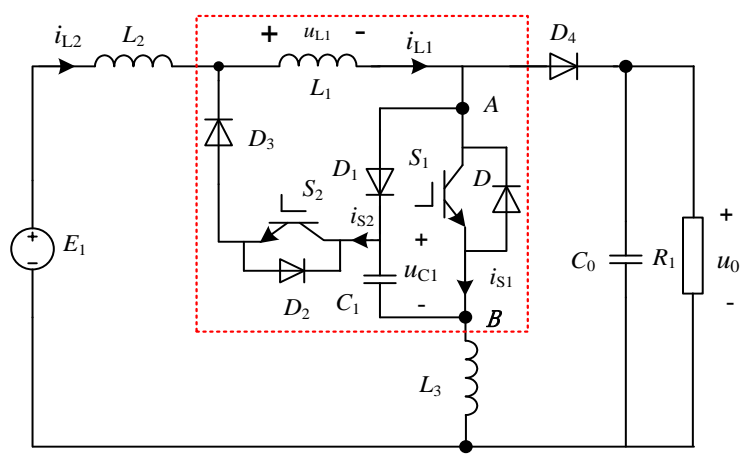

Fig. 1. Boost soft-switching converter.

\subsection{Mode Analysis}

The electronic devices in the circuit can be regarded ideally, the photovoltaic arrays are considered as ideal voltage source as well. Resonant inductors $L 1$ and $L 2$ are two split inductors of main inductor of boost converter, with a value of $L / 2$, meanwhile, the value of resonant inductor s $L 1$ and $L 2$ are far more than resonant inductor $L 3$, therefore, the resonant inductors $L 3$ is neglected, the circuit has seven circuit working modes:

\subsubsection{Working mode $1\left[t_{0}, t_{1}\right]$}

Fig. 2 shows the equivalent circuit of mode 1 , the voltage of resonant capacitor $C_{1}$ reach to its peak value $U_{0}$ before $t_{0}$. At $t_{0}$, the auxiliary switch achieve zero-current turn-on. After $t_{0}$, the current $i_{S 2}$ flowing through auxiliary switch $S_{2}$ increase nonlinearly and the current flowing through resonant inductor $L_{1}$ increase linearly, while the current $i_{L 2}$ flowing through resonant inductor $L_{2}$ decrease linearly and the voltage of resonant capacitor $C_{1}$ decrease nonlinearly. All the parameters change as following:

$$
\begin{gathered}
u_{L 1}=u_{C 1}-u_{0} \\
u_{L 1}=L_{1} \frac{d i_{L 1}}{d t} \\
i_{L 1}=C_{0} \frac{d u_{C 0}}{d t}+\frac{u_{0}}{R_{1}}
\end{gathered}
$$

The followings can be obtained from the formulas (1)、(2)、(3):

$$
\begin{gathered}
\frac{d i_{L 1}}{d t}=\frac{2 u_{L 1}}{L} \\
\frac{d u_{C 0}}{d t}=\frac{1}{C_{0}} i_{L 1}-\frac{u_{C 0}}{R_{1} C_{0}}
\end{gathered}
$$




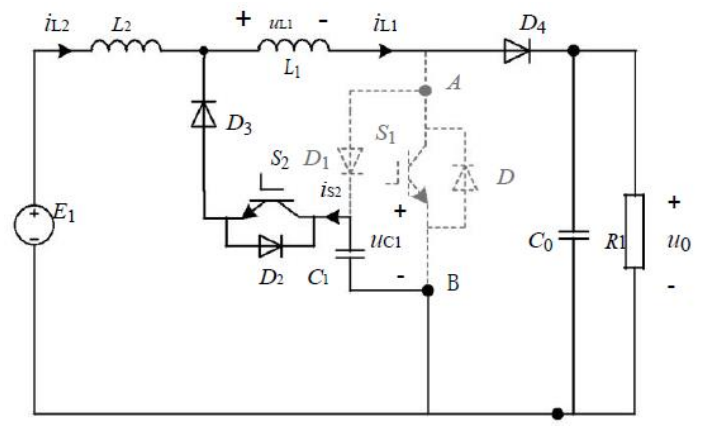

Fig. 2. Boost soft-switching converter.

\subsubsection{Working mode $2\left[t_{1}, t_{2}\right]$}

At $t_{1}$, the main switch $S_{1}$ achieve zero- current turn-on. After $t_{1}$, the current $i_{\mathrm{S} 1}$ flowing through main switch $S_{1}$ increase linearly and the diode $D_{4}$ cut off. The resonant capacitor $C_{1}$ continues to discharge to inductors $L_{1}$ and $L_{2}$, the current $i_{\mathrm{L} 1}$ flowing through resonant inductor $L_{1}$ increase linearly, while the current $i_{\mathrm{L} 2}$ flowing through resonant inductor $L_{2}$ decrease slowly. The voltage of resonant capacitor $C_{1}$ decrease nonlinearly till $t_{2}$, at which the voltage $u_{\mathrm{C} 1}$ of resonant capacitor $C_{1}$ reach to zero and the current i $_{\mathrm{S} 1}$ flowing through main switch $S_{1}$ reach its maximum. The variation of some parameters change as following formulas:

$$
\begin{gathered}
L_{2} \frac{d i_{L 2}}{d t}+L_{1} \frac{d i_{L 1}}{d t}=E_{1} \\
\frac{d u_{C 0}}{d t}=\frac{1}{C_{0}} i_{L 1}-\frac{u_{C 0}}{R_{1} C_{0}}
\end{gathered}
$$

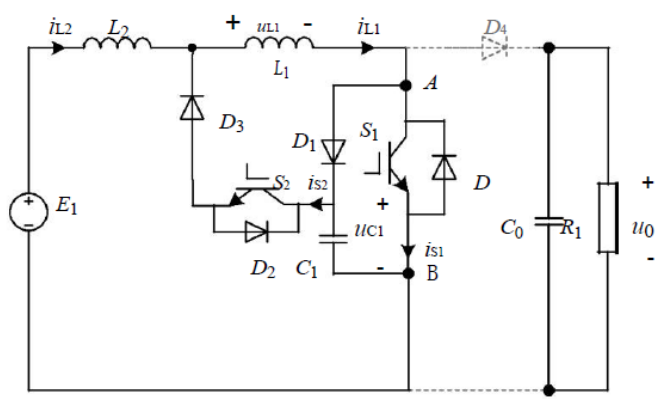

Fig. 3. Working mode $2\left[t_{1}, t_{2}\right]$.

\subsubsection{Working mode $3\left[t_{2}\right]$}

The voltage $u_{C 1}$ of resonant capacitor $C_{1}$ become zero at $t_{2}$, the diode $D_{1}$ is on conduction.

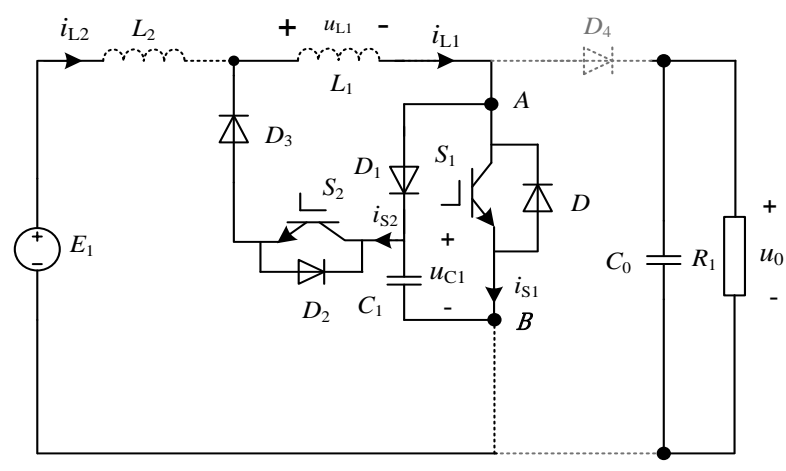

Fig. 4. Working mode $3\left[t_{2}\right]$. 


\subsubsection{Working mode $4\left(t_{2}, t_{3}\right)$ :}

After $t_{2}$, resonant inductor $L_{1}$ start to charge to resonant capacitor $C_{1}$, the voltage between diode and resonant capacitor $C_{1}$ is zero. According to Kirchhoff laws, the current $i_{S 1}$ flowing through main switch $S_{1}$ decrease rapidly, while the current $i_{\text {s2 }}$ flowing through auxiliary switch $S_{2}$ decrease gradually. In addition, the current of resonant inductor $L_{1}$ keep constant, the current flowing through resonant inductor $L_{2}$ increase until $t_{3}$, when the current of two resonant inductors are same, the circuit turns into next working mode.

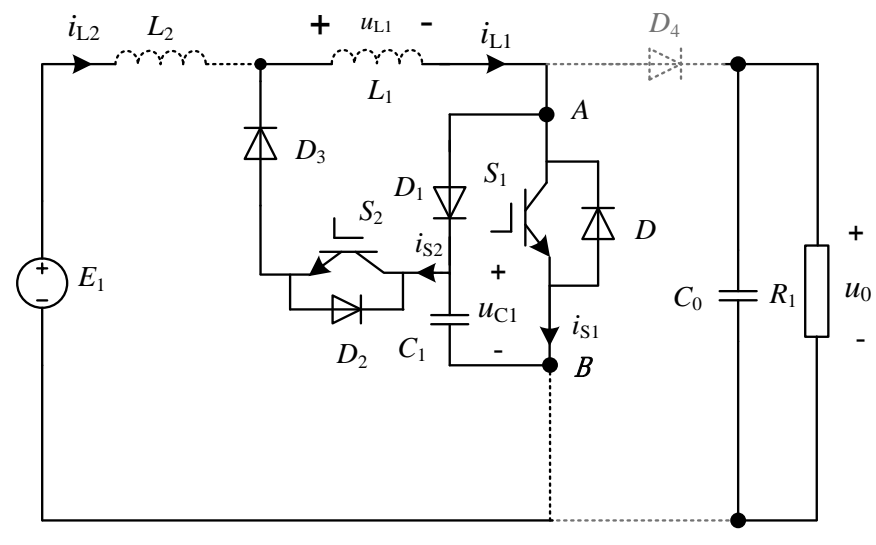

Fig. 5. Working mode $4\left(t_{2}, t_{3}\right)$.

\subsubsection{Working mode $5\left[t_{3}, t_{4}\right]$}

At $t_{3}$, the current $i_{L 2}$ flowing through resonant inductor $L_{2}$ equals the current $i_{L 1}$ flowing through resonant inductor $L_{1}$, the diodes $D_{1}$ and $D_{2}$ cut off, so the current $i_{S 2}$ of auxiliary switch $S_{2}$ become zero. After $t_{3}$, the current of resonant inductors $L_{1}$ and $L_{2}$ increase gradually.

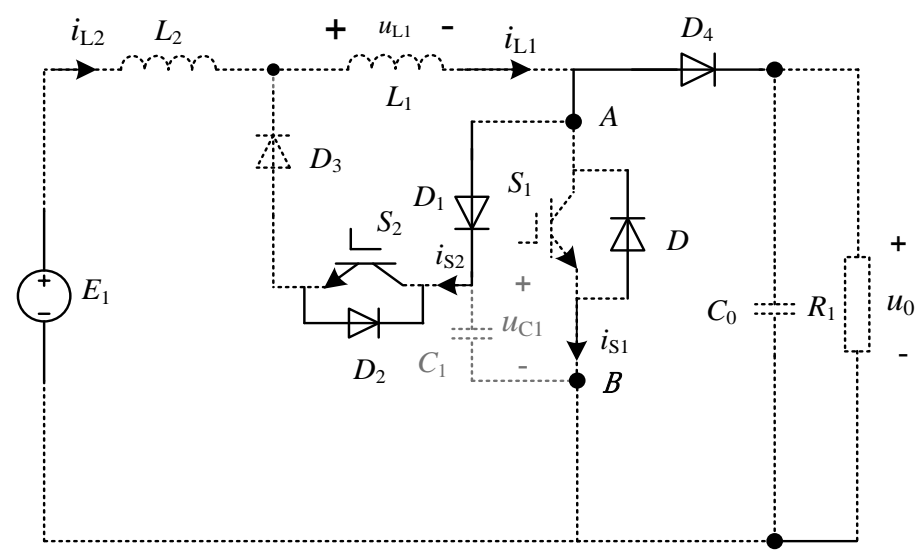

Fig. 6. Working mode $5\left[t_{3}, t_{4}\right)$.

\subsubsection{Working mode $6\left[t_{4}, t_{5}\right]$}

At $t_{4}$, the current flowing through main switch $S_{1}$ reach its maximum value, but the current flowing through auxiliary switch $S_{2}$ become zero, which achieve zero-current turn-off, and the main switch turn off. After $t_{4}$, the diode $D_{1}$ is on conduction. The resonance among resonant inductors $L_{1} 、 L_{2}$ and resonant capacitor $C_{1}$ make the voltage $\mathrm{u}_{\mathrm{C} 1}$ of resonant capacitor $C_{1}$ increase gradually and the current of resonant inductors $L_{1} 、 L_{2}$ decrease slowly till $t_{5}$, when the voltage $u_{C 1}$ of resonant capacitor $C_{1}$ reach its peak value $U_{0}$. All the parameters change as following: 


$$
\frac{d i_{L 1}}{d t}=-\frac{1}{L} u_{0}+\frac{E_{1}}{L}
$$

$$
\frac{d u_{0}}{d t}=-\frac{1}{C_{0}} i_{L 1}-\frac{1}{C_{0} R_{1}} u_{0}
$$

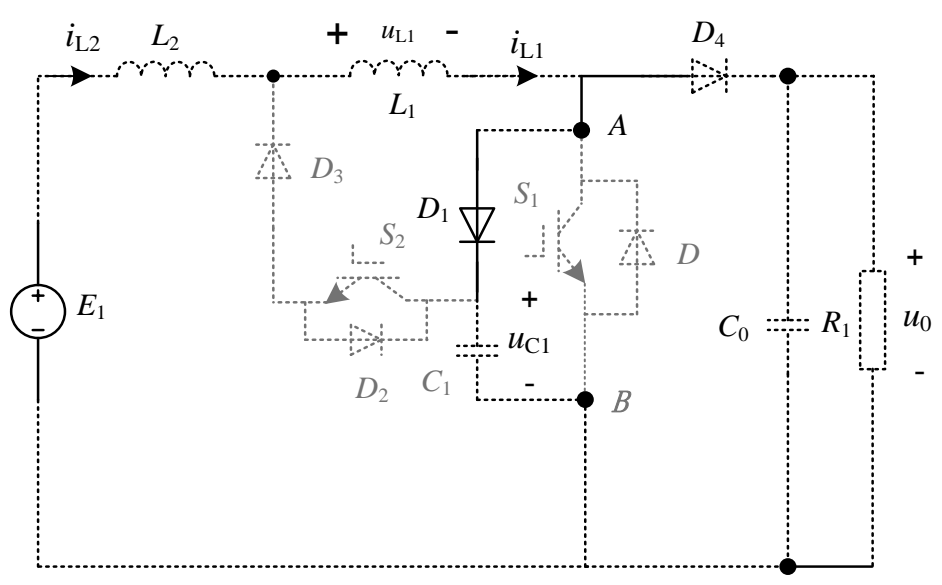

Fig. 7. Working mode $6\left[t_{4}, t_{5}\right)$.

\subsubsection{Working mode $7\left[t_{5}, t_{6}\right]$}

At $t_{5}$, the voltage $u_{\mathrm{C} 1}$ of resonant capacitor $C_{1}$ become maximum, resonant capacitor $C_{1}$ and direct power supply charge to resonant inductors $L_{1}$ and $L_{2}$ until $t_{6}$. The circuit is equivalent to boost converter, releasing energy in this process. and the circuit turn into next working cycle.

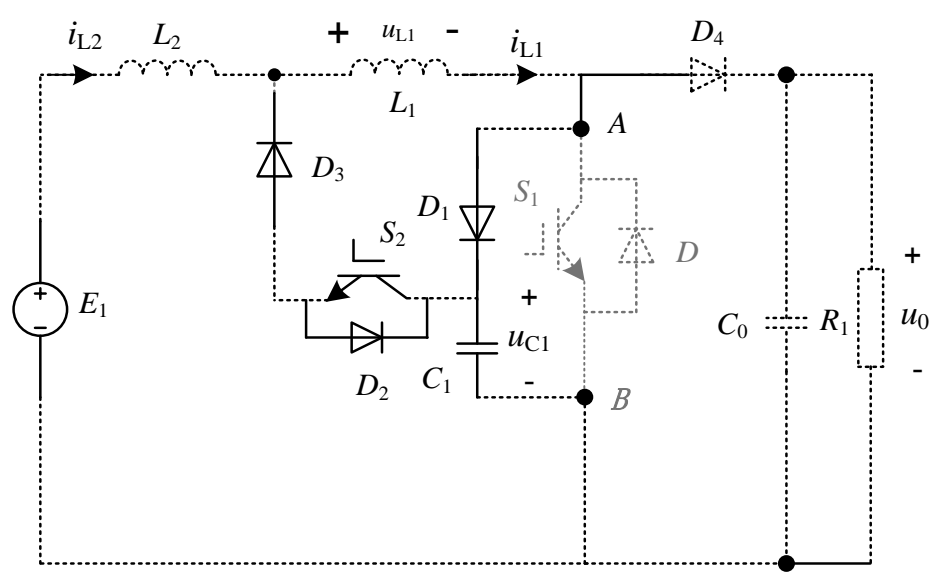

Fig. 8. Working mode $6\left[t_{5}, t_{6}\right)$.

\section{Traditional Modulation Strategy}

The main switch $S 1$ can only achieve zero-current turn-on at $t_{1}$ from mode 3 , but both of the current and the voltage of main switch $S 1$ are zero, so it can achieve zero-current zero-voltage turn-on at $t_{2}$. The current and voltage of auxiliary switch $S 2$ are zero at $t_{3}$ from mode 5 , so it can achieve zero-current zero-voltage turn-off. Fig. 9 illustrates traditional modulation strategy, whose solid arrow indicates the turn-on time of main switch and the turn-off time of auxiliary switch needed to improve. Furthermore, the dotted line shows the direction needed to change. 


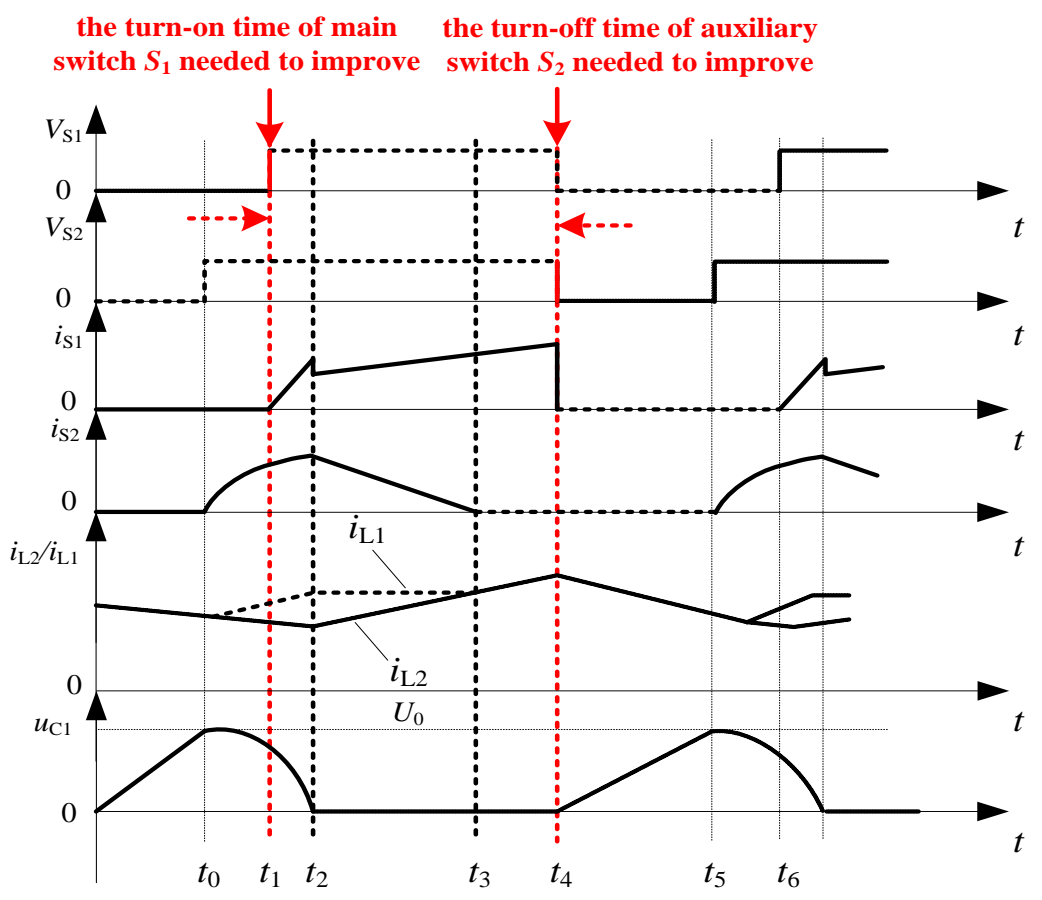

Fig. 9. Traditional modulation strategy.

\section{Improved Modulation Strategy}

The main switch $S_{1}$ in Fig. 9 can only achieve zero-current turn-on at $t_{1}$, however, the improved modulation strategy in Fig. 10, whose turn-on time of main switch $S_{1}$ is moved to the right along the abscissa, can make main switch $S_{1}$ achieve zero-current zero-voltage turn-on. The auxiliary switch $S_{2}$ in Fig. 9 can turn off at $t_{4}$, while the turn-off time of auxiliary switch $S_{2}$ in Fig. 10 moves from $t_{4}$ to $t_{3}$, with zero-current zero-voltage turn-off. The improved modes are as following:

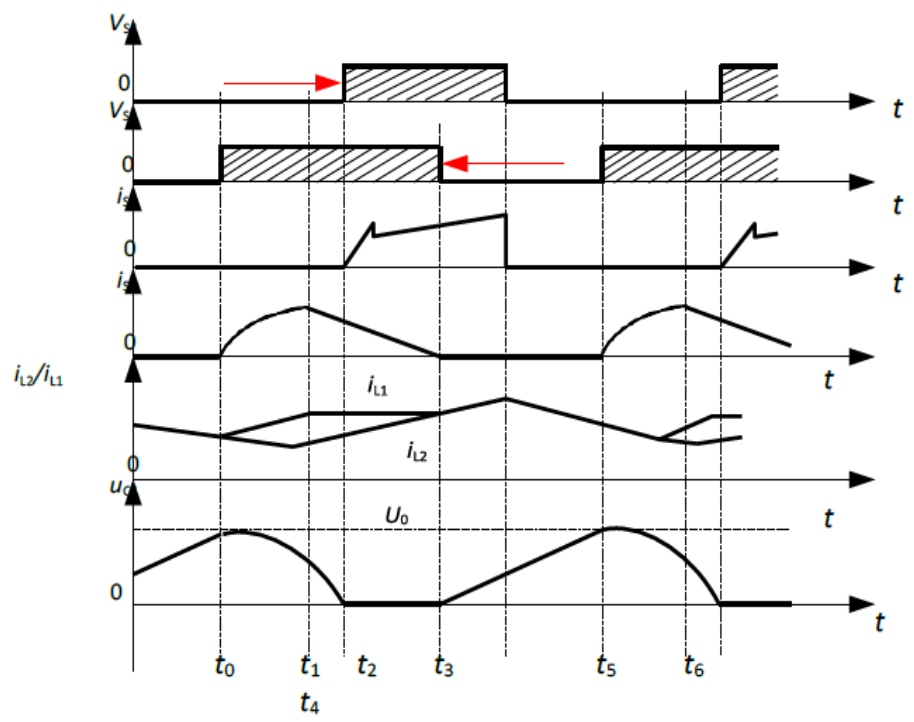

Fig. 10. Improved modulation strategy.

\subsection{Working Mode $3\left[t_{2}\right]$ :}

As the voltage $u_{\mathrm{C} 1}$ of resonant capacitor $C_{1}$ is zero and the diode $D_{1}$ is on conduction, the voltage between 
diode $D_{1}$ and resonant capacitor $C_{1}$ is zero, meanwhile, the current flowing through the main switch $S_{1}$ is zero, so it is easily for the main switch $S_{1}$ to achieve zero-current zero-voltage turn-on.

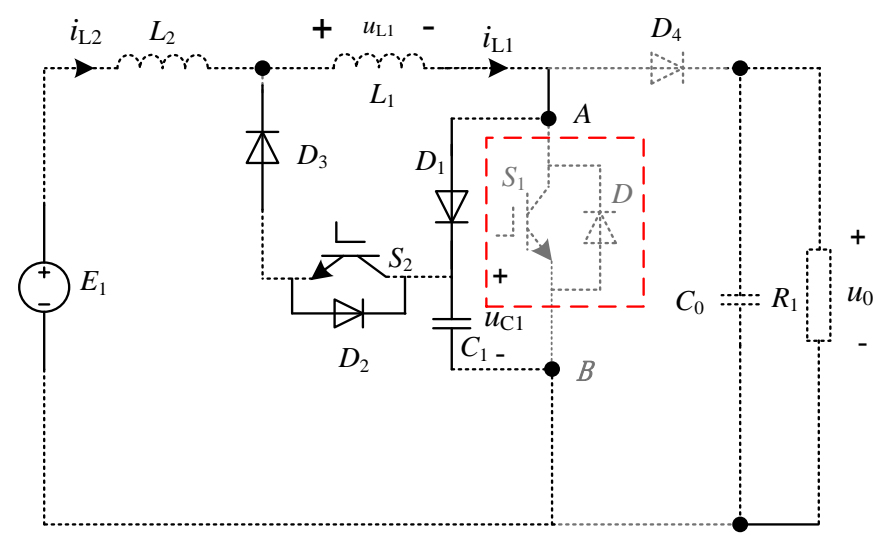

Fig. 11. Working mode $3\left[t_{2}\right]$.

\subsection{Working Mode $5\left[t_{3}, t_{4}\right]$}

At $t_{3}$, the current flowing through resonant inductor $L_{2}$ equals the current flowing through resonant inductor $L_{1}$, so the current of auxiliary switch $S_{2}$ is zero according to Kirchhofflaws.

In addition, the current flowing through resonant inductor $L_{1}$ stay constant from $t_{2}$ to $t_{3}$, leading to the voltage of auxiliary switch $S_{2}$ become zero, therefore, the auxiliary switch $S_{2}$ can achieve zero- current zero-voltageturn-off.After $t_{3}$, the circuitis equivalentto energystorage process ofboost.

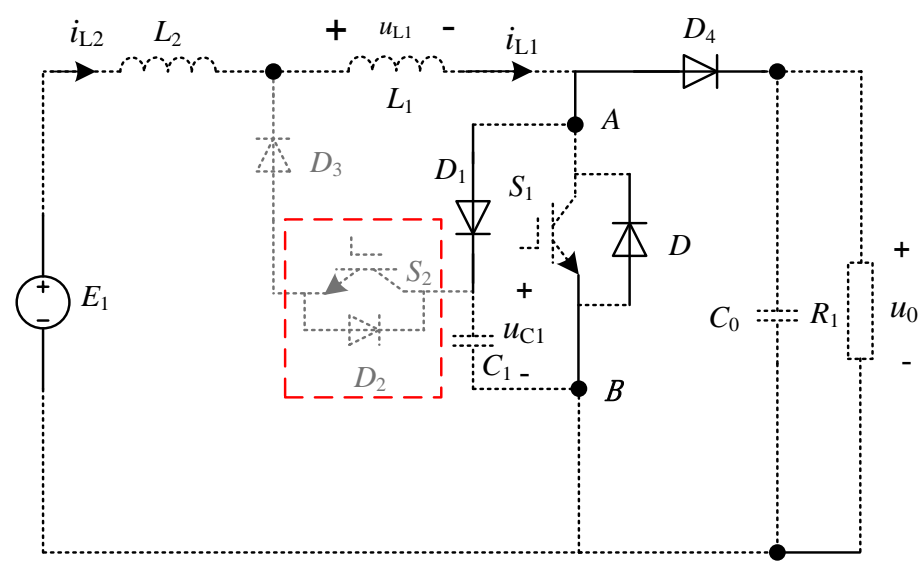

Fig. 12. Working mode $3\left[t_{3}, t_{4}\right)$.

\section{Simulation Verification}

\subsection{Parameter Settings}

Table 1 is the parameter settings of circuit, whose resonant inductors $L_{1}$ and $L_{2}$ are equivalent.

Table 1. Parameter Settings

\begin{tabular}{cccc}
\hline \hline Input Voltage $E 1$ & 200V & Resonant Inductor $L 3$ & $\mathbf{0 . 8 m H}$ \\
\hline Ouput Voltage $u 0$ & $400 \mathrm{~V}$ & Resonant Capacitor $\boldsymbol{C 1}$ & $0.33 \mathrm{uF}$ \\
Resonant Inductors $L 1 、 L 2$ & $10 \mathrm{mH}$ & Frequency $f \mathbf{k}$ & $25 \mathrm{kHz}$ \\
\hline \hline
\end{tabular}




\subsection{Parameter Settings}

Fig. 13 illustrates main switch and auxiliary switch driving signals of primary circuit, the voltage VP1 and the current $I_{1}$ of main switch, the main switch $S_{1}$ can only achieve zero-current turn-on.

Fig. 14 illustrates main switch and auxiliary switch driving signals of improved circuit, the voltage VP1 and the current $I_{1}$ of main switch, the main switch $S_{1}$ can achieve zero-current zero-voltage turn-on at $t_{2}$.

Fig. 15 shows main switch and auxiliary switch driving signals of primary circuit, the voltage VP2 and the current I 2 of auxiliary switch, the auxiliary switch $S_{2}$ can achieve zero-current zero-voltage turnoff at $t_{4}$.

Fig. 16 shows main switch and auxiliary switch driving signals of improved circuit, the voltage VP2 and the current I2 of auxiliary switch. Compared to Fig. 15, the auxiliary switch $S_{2}$ in Fig. 16 can achievezero-currentzero-voltage turn-off before $t_{4}$.

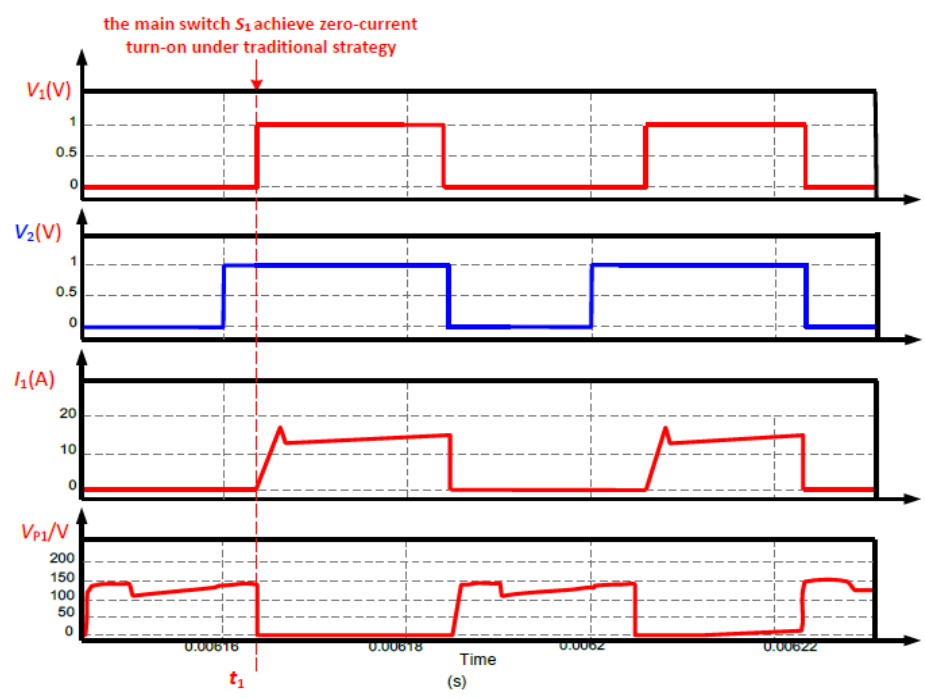

Fig. 13. Driving signals of primary circuit and the voltage and current of main switch.

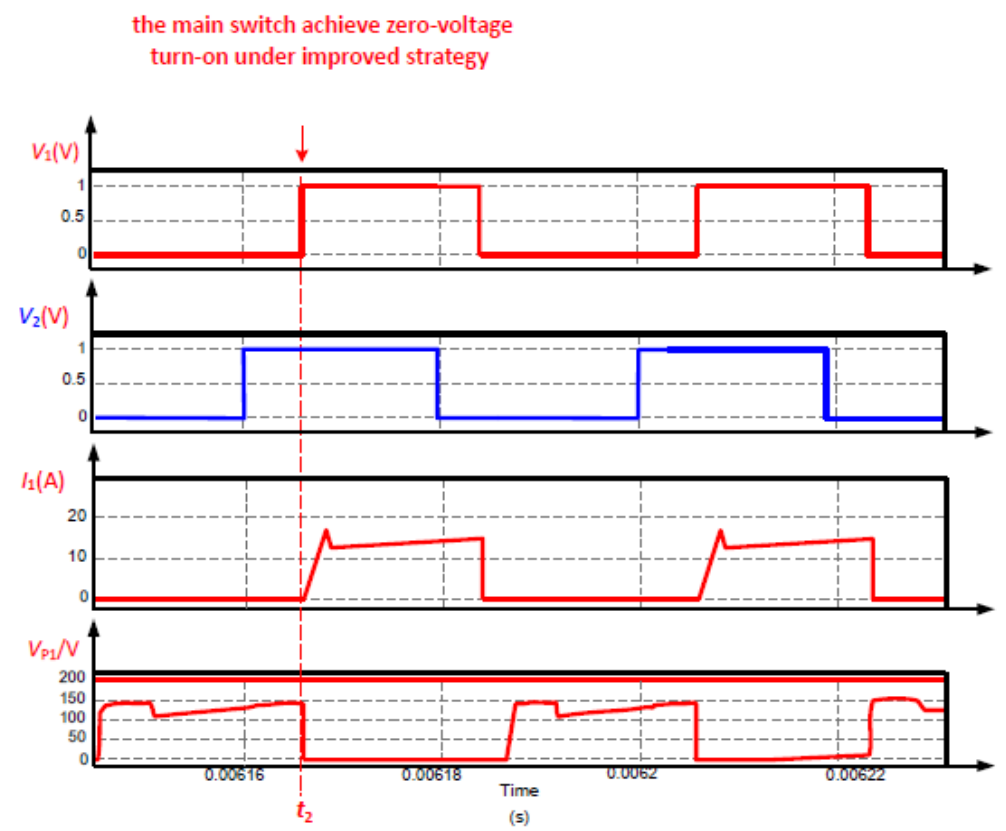

Fig. 14. Driving signals of improved circuit and the voltage and current of main switch. 


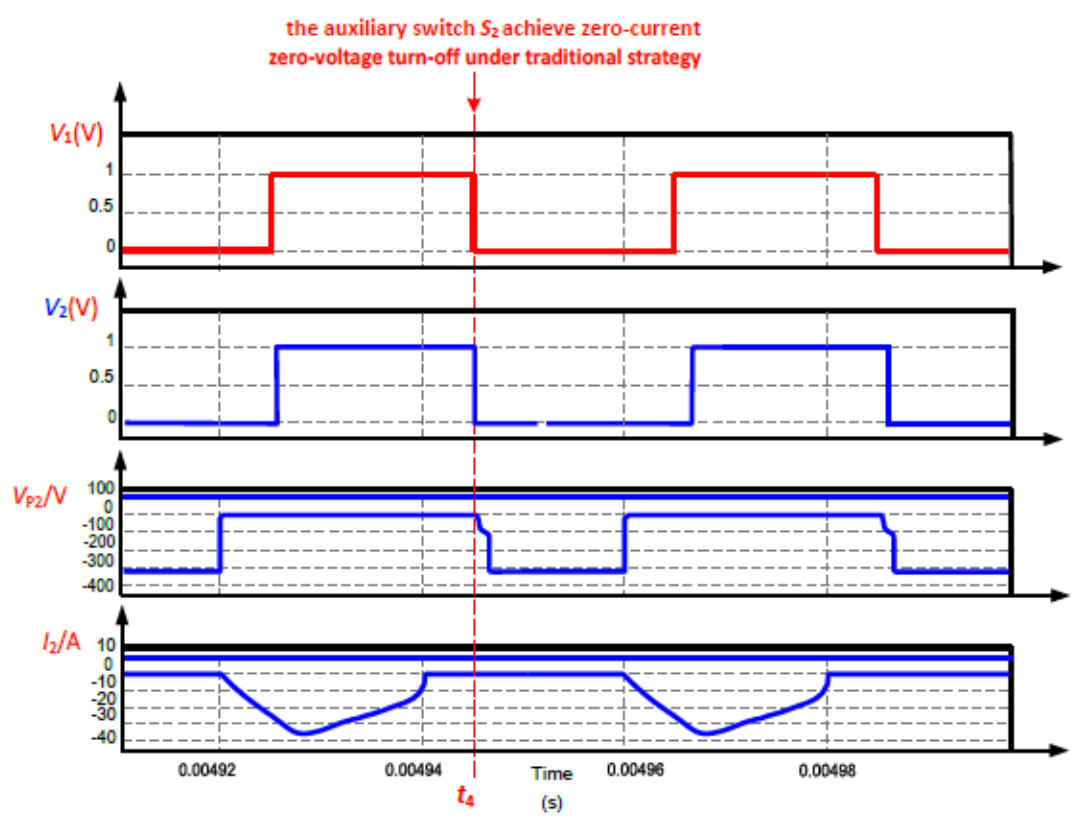

Fig. 15. Driving signals of primary circuit and the voltage and current of auxiliary switch.

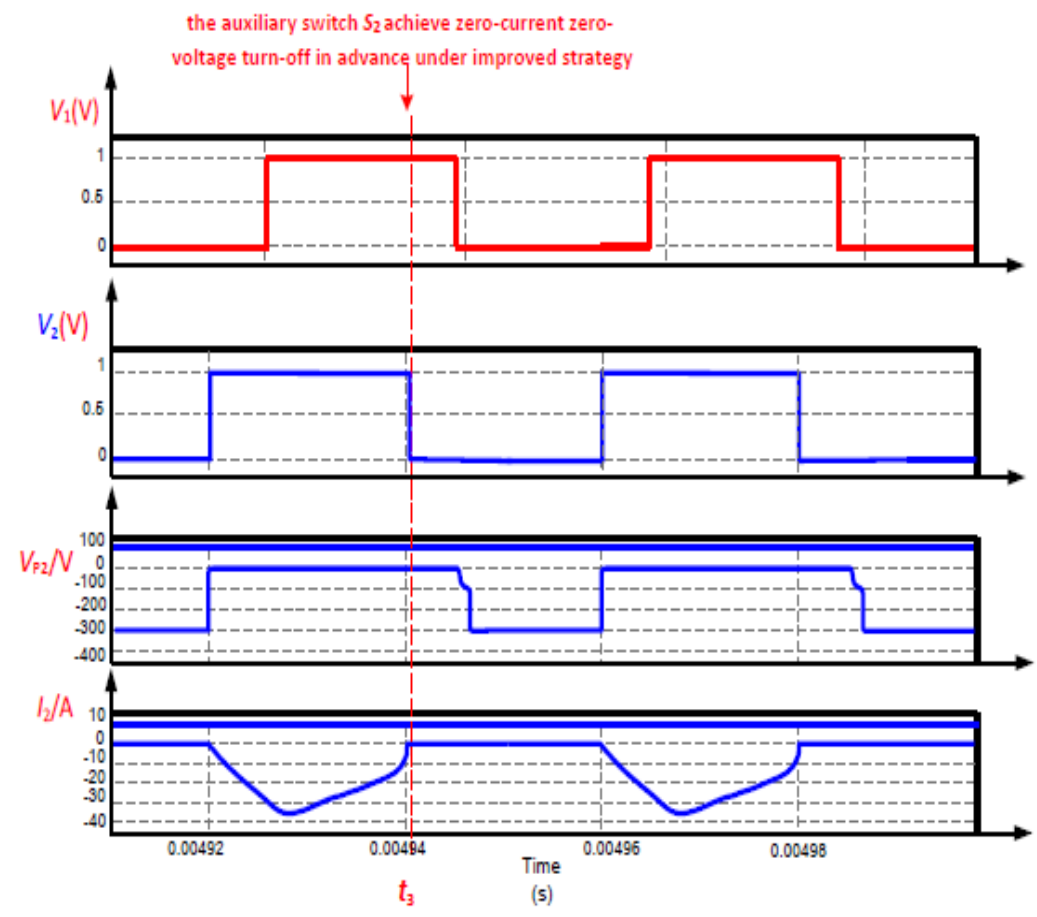

Fig. 16. Driving signals of improved circuit and the voltage and current of auxiliary switch.

Compare Fig. 13 with Fig. 14, it is obvious that the energy stored in resonant capacitor $C_{1}$ is transferred to resonant inductor completely at $t_{2}$. The voltage between diode $D_{1}$ and resonant capacitor $C_{1}$ is zero, while the current flowing through main switch $S_{1}$ is zero. Therefore, it is easily for the main switch $S_{1}$ achieve zero-current zero-voltage turn-on. Compare Fig. 14 with Fig. 15, it is apparent that the auxiliary switch $S_{2}$ achieve zero-current zero-voltage turn-off at $t_{3}$ under the improved driving signals of main switch and auxiliary switch.

At $t_{3}$, the current of resonant inductor $L_{2}$ is equivalent to the current of resonant inductor $L_{1}$ and the current flowing through auxiliary switch $S_{2}$ is zero. As the current flowing through resonant inductor $L_{1}$ 
stay constant from $t 2$ to $t 3$, so the voltage of auxiliary switch $S_{2}$ is zero, which can achieve zero-current zero-voltage turn-off at $t_{3}$.

\section{Conclusion}

According to the analysis above, the improved modulation strategy based upon zero-voltage zero-current transition boost converter can make main switch achieve zero-voltage zero-current turn-on. However, the change to the turn-on time of main switch can make the main switch achieve zero-voltage zero-current turn-on, and the change to the turn-off time of auxiliary switch can realize the zero-voltage zero-current turn-off of auxiliary switch in advance as well. The change to the open time and close time can reduce the power loss of switches in chopper circuit. The simulation results verify the correctness of improvement. The way to change the modulation strategy can be applied to chopper circuit.

\section{References}

[1] Wang, X. M., \& Zhang, B. (2012). A Review of DC-DC c onverter technology. Magnetic Components and Power, 2012(5), 138-141.

[2] Faqhruldin, O. N., El-Saadany, E. F., \& Zeineldin, H. H. (2014). A universal islanding detection technique for distributed generation using pattern recognition. IEEE Trans. on Smart Grid, 5(4), 1985-1992.

[3] Akin, B. (2014). An improved ZVT-ZCT PWM DC-DC boost converter with increased efficiency. IEEE Transactions on Power Electronics, 29(4), 1919-1926.

[4] Han, D. W., Lee, H. J., Shin, S. C., et al. (2012). A new soft switching ZVT boost converter using auxiliary resonant circuit[C]. Proceedings of Vehicle Power and Propulsion Conference (pp. 1250-1255).

[5] Altintas, N., Bakan, F., \& Aksoy, I. A novel ZVT-ZCT-PWM boost converter. IEEE Transactions on Power Electronics, 29(1), 256-265.

[6] Ting, N. S., Sahin, Y., \& Aksoy, I. (2015). A new ZCT-ZVT PWM interleaved DC-DC boost converter. Proceedings of Intl Aegean Conference on Electrical Machines \& Power Electronics.

[7] Altintas, N., Bakan, F., \& Aksoy, I. (2014). A novel ZVT-ZCT-PWM boost converter. IEEE Transactions on Power Electronics, 29(1), 256-265.

[8] Shin, J. W., Chae, S. Y., \& Cho, B. H. (2009). A new zero current transition boost converter using split inductors. China Electrotechnical Society, IEEE Power Electronics Society, National Science Foundation of China. Proceedings of 2009 IEEE 6th International Power Electronics and Motion Control Conference-ECCE Asia Conference Digests. China Electrotechnical society, IEEE Power Electronics Society, National Science Foundation ofChina.

[9] Cui, W., Yang, B., Zhao, Y., et al. (2011). A novel single-phase transformerless grid-connected inverter. Proceedings of Conference of the IEEE Industrial Electronics Society (pp. 1126-1130).

[10] Chu, E. H., \& Yu, W. M., (2009). An kind of zero-voltage zero-current transition converter chopper circuit. Motor and Control,13(4), 477-482.

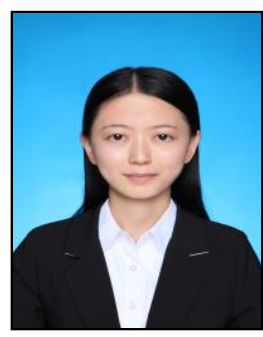

Yingjie Xiong is the first author, whose place of birth is Yichun city, in Jiangxi provenience, and the date of birth is on April 13, 1991. In 2016, she was an electrical engineering and information postgraduate graduated from Jiangsu University, in Zhenjiang city of China, whose major field of study is solar photovoltaic power generation.

She is working in Shangrao Power Supply Branch, Jiangxi Electric Power Company, State Grid after she graduated from Jiangsu University as an outstanding graduate. The 
published papers during studying in the school were as follows:

Papers:

[1] The Improvement of Zero-current-transition H6 Type Transformerless PV Grid-connected Inverter [J]. Journal of Computational Information Systems, 2015, 672: 1219-1223. (EI)

[2] Research on Torque Ripple of IPM Synchronous Machine based on Optimal Shape Design in Rotor [J]. Journal of Computational Information Systems, 2015.11 [19]6901-6909. (EI)

[3] Research review on the suppression techniques of leakage current on non-isolated photovoltaic grid-connected inverters[J] Electrical Measurement \& Instrumentation (in Chinese) 2015, 52(22): 100-107 (Chinese Core). 